\title{
A SHORT REVIEW ON THE USE OF SHORT TANDEM REPEAT BASED DNA PROFILING IN SEXUAL ASSAULT
}

\author{
Afraah Cassim \\ School of Science, BMS, Colombo, Sri Lanka
}

Corresponding author: Afraah Cassim

Email:afraahcee@gmail.com

https://orcid.org/0000-0001-5257-8056

\begin{abstract}
Forensic DNA evidence can convict perpetrators who would otherwise have escaped, hence the reason for its growth in case evidence over the years. Short Tandem Repeat (STR) profiling, continues to be the mainstay for forensic DNA testing due to its robustness and high power of discrimination. The 'core STRs' in forensics, are highly polymorphic, and unique to an individual, therefore proven as important investigative leads in cases of identification of perpetrators in sexual assault, thereby ensuring justice. The common STRs used to date are autosomal STRs, Y-STRs, mini STRs and recently, Deletion Insertion Polymorphism-STRs. This article reviews current literature and discusses the advantages and limitations of each STR marker and their targets in different challenging samples. It aims to provide intuition on minimising ambiguous profiles for case evidence in sexual assault and thereby, reduce the chances of wrongful conviction by DNA evidence.
\end{abstract}

Keywords: DIP-STR, mini STR, sexual assault, short tandem repeat, Y-STR

All articles in Sri Lanka Journal of Forensic Medicine, Science \& Law are licensed under the terms of the licensed under a Creative Commons Attribution-Non Commercial 4.0 International License. 


\section{INTRODUCTION}

The method of "DNA fingerprinting" discovered by Sir Alec Jeffreys in 1980s is used globally by forensic scientists, for exonerating innocent and convicting guilty individuals. DNA evidence for sexual assault has led to numerous successful convictions, but has also led to a few wrongful convictions ${ }^{1,2}$.

During the first decade of DNA forensic testing, STR profiling was evolving fast due to the small amounts of DNA required for testing, its robustness and high discrimination power ${ }^{3,4}$. Thus in 2011 , it was reported that $77 \%$ of sexual assault cases were resolved successfully by STR profiling ${ }^{3}$.

STRs are made up of 2-7 base pair repeating units, found mostly in the non-coding region of DNA and spans extensively across the human genome. STR profiling in forensics involves isolation of DNA from biological samples collected, most commonly by either swabs off skin, body fluids or 'touch DNA' found at a crime scene. The STRs are then amplified by polymerase chain reaction (PCR) and analysed by polyacrylamide capillary or slab gel electrophoresis and the results are matched with the suspects samples, or from profiles gathered from a national DNA database ${ }^{4,5}$.
Since autosomal STRs were the initial STR markers developed, they occupy the largest established national DNA databases to date, which far exceed Single Nucleotide Polymorphisms (SNP's) and any other STR marker ${ }^{4,6}$. Novel STR methods such as Y chromosome STR profiling, mini STR profiling and during the recent years, Deletion Insertion Polymorphism (DIP)STRs analysis' have been implemented into case evidence. Each of these markers target different challenging samples, to generate profiles for case evidence in sexual assault, which will be discussed in this review ${ }^{7,8}$.

\section{Analysis of the types of STR profiling used in case evidence in literature}

\section{Autosomal Chromosome STR Profiling}

Autosomal STR typing was used in the 1990s, and in 2002, an interesting rape case used autosomal STR analysis to generate profiles without evidence samples from the crime scene itself. The case involved a rape of a girl who conceived after rape. The crime was investigated four months later, and sperm typing was unable to confirm the perpetrator. Therefore, DNA was extracted from blood of the victim, 4 suspects and skin tissue of the foetus. Analysis of 6 STR loci were done, and the allele types for one locus are shown here (Table 1) ${ }^{9}$.

Table 1: Results for one STR locus analysed on $4 \%$ polyacrylamide gel ${ }^{9}$

\begin{tabular}{|l|l|l|l|l|l|l|}
\hline Locus & $\begin{array}{l}\text { Victim } \\
\text { (mother) }\end{array}$ & Foetus & Suspect 1 & Suspect 2 & Suspect 3 & Suspect 4 \\
\hline \multirow{2}{*}{ CSF1PO } & 10 & $10(\mathrm{~m})$ & 11 & 10 & 11 & 11 \\
\cline { 2 - 8 } & 10 & $11(\mathrm{p})$ & 13 & 10 & 13 & 12 \\
\hline
\end{tabular}

Taking the first locus (CSF1PO) as an example; the foetus has alleles 10 and 11 , with 10 arising from the mother since she is homozygous for allele 10 . The suspect 2 can be excluded since the individual is also homozygous for allele 10 and cannot be the donor of allele 11 of the foetus. Different genotype at one locus at least, is the rule for exclusion in any STR profiling work as highlighted in this particular case. The individual specific nature of STRs prove to give this technique high discriminatory power over other techniques ${ }^{6}$. 
In contrast to only making exclusions, inclusions of suspects in a criminal case involve autosomal STR profiling at multiple loci, regardless of the number of suspects. Blood samples from a suspect were obtained, along with the semen stain recovered from the victim's dress. The use of 9 autosomal STR loci confirmed the perpetrator was the suspect ${ }^{4}$.

\section{Y Chromosome STR Profiling}

Y-STR profiling specifically resolves male components in a mixture to generate a DNA profile allowing a match or exclusion of an individual in a crime investigation ${ }^{6,10}$. When evidence contains both male and female DNA, autosomal STR typing has male DNA detection sensitivity at a male to female ratio of 1:50, whereas Y-STR typing can detect male DNA at a ratio of 1:2000 .

However, a rare case of wrongful conviction by Y-STR profiling took place after an innocent individual was convicted for 2 years due to a coincidental match of a 17loci Y-STR profile in an alleged case of sexual assault. Re-evaluation was carried out after the conviction, using 23 loci, where 2 loci did not match the suspect, and the guilty verdict for the alleged suspect was reversed $^{11}$.
This shows that a match profile alone, cannot determine guilt or innocence. Since Y-STR is not sufficiently discriminatory, it is best advised to perform both autosomal and Y-STR profiling and increase the number of loci to increase the validity of the test $^{12,13}$. Use of combination of the two, provided highly informative profiles for $21 \%$ of the cases ${ }^{14}$.

Another major drawback of routine Y-STR profiling kits, is the inability to differentiate paternally related males ${ }^{15}$. To overcome this, Ballantyne and colleagues proposed the use of 13 Rapidly Mutating (RM) Y-STRs where the mutation rate is $1 \times 10^{-2}$ and in comparison to Y-STR mutation rate $1 \times 10^{-3}$. 16 Studies into RM Y-STRs in 2012, by Ballantyne and colleagues confirmed a 4.4fold increase of average male differentiation in comparison to $\mathrm{Y}-\mathrm{STRs}^{16}$. This notion was further supported by Adnan and colleagues in 2016, when a 7-fold increase of differentiation of paternal relatives in comparison to Y-STRs, highlighting the importance of their use ${ }^{17}$.

Other successful Y-STR profiling studies and the age of evidence samples used are given in (Fig. 1) ${ }^{6,10,13,18,19,20}$. Typically, most cases fall between 3-9 days out of the time frame of one year. But samples that exceed 3-9 days, are less procured by YSTR profiling. Hence the need for mini STR profiling arises.

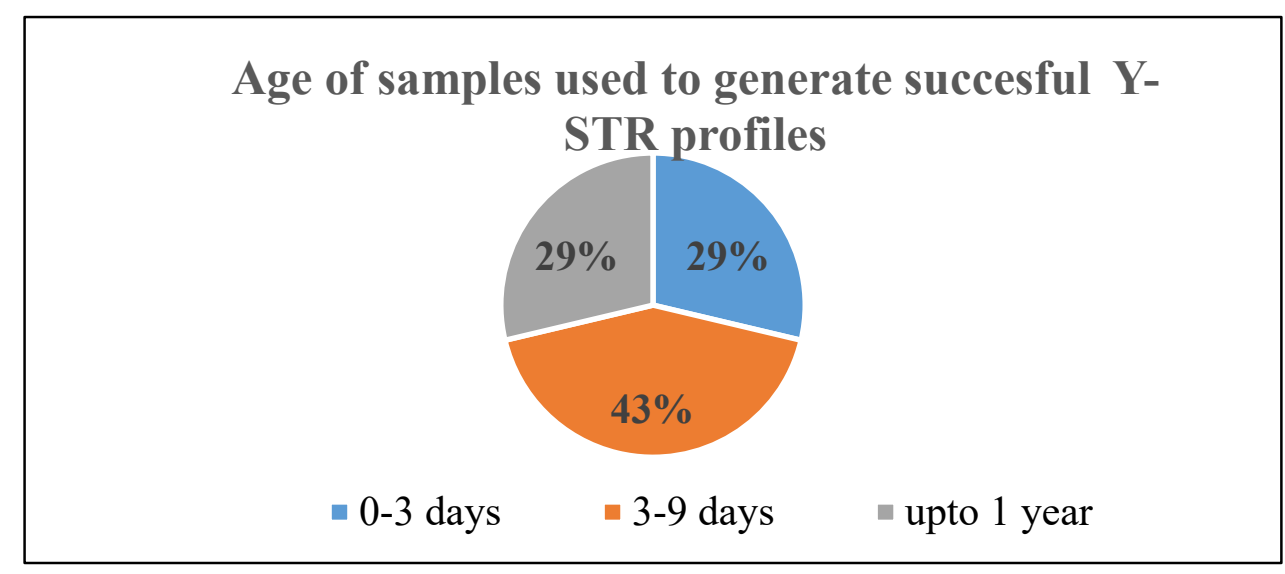

Figure 1: The age of the sample used, and the respective number of cases for each age category 


\section{Mini STR profiling}

Mini STR profiling involves primers which target the DNA sequence closer to the repeat region unlike conventional STR primers; thus, generating shorter amplicons ${ }^{7,21}$.
Since only about $31 \%$ of the sexual assault offenses are reported at the time of the incident, mini STRs' as shown in (Fig. 2), are known to be effective in processing aged samples with low template/degraded DNA $^{22,23}$.

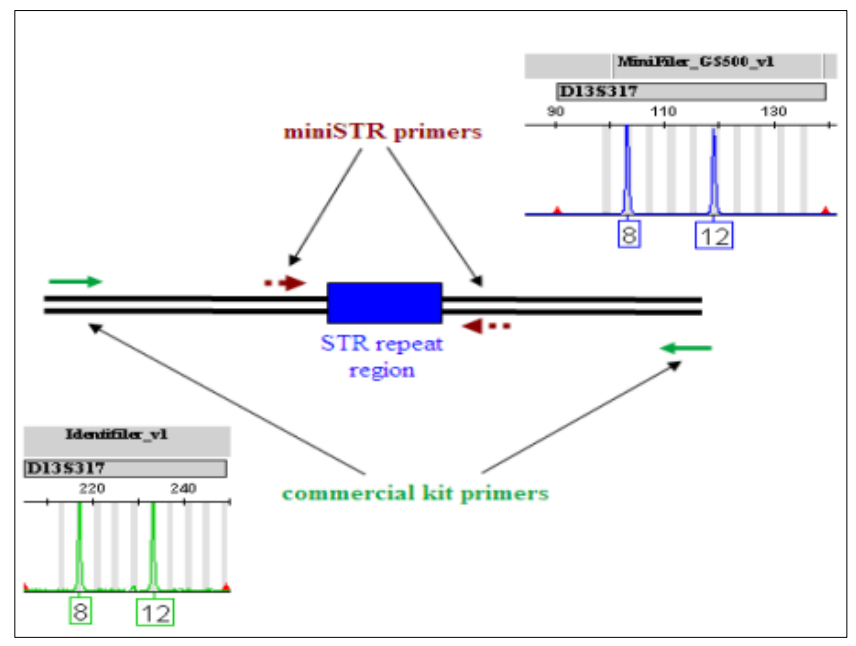

Figure 2: D13S317 Locus: Conventional STR primer (green) generate amplicons of 200-250bp, Mini STR primer (blue) generate amplicons of 100-150bp, closer to the repeat region. ${ }^{24}$

DNA evidence in court has been doubtful since it depends on the age and volume of sample to generate successful profiles, and it is understood that vaginal pool evidence reduces after one day ${ }^{22,23}$. Avoiding the DNA extraction steps and increasing PCR cycles is essential when DNA is degraded/ present in trace amounts ${ }^{25,26}$. However, direct STR profiling or increasing the number of PCR cycles would generate more PCR non-specific amplifications, since other cell contaminants are also amplified. Moreover, using mitochondrial DNA profiling is not time and cost effective, thus the growth of mini STR profiling in case evidence ${ }^{21}$.

A case of sexual assault was re-analysed twelve years after the incident occurred, and a sample of $2 \mathrm{ng} / \mu \mathrm{l}$ was collected from a stained slide. Analysis by conventional autosomal STR profiling revealed only the victim's profile. But, when mini STR profiling was proceeded, two profiles were generated, one from the victim and the other from the prime suspect in the case, highlighting the mini STRs' higher efficacy in generating profiles for all the contributors ${ }^{24}$.

In addition to the type of sample used, the age of the samples and their degradation index ratios (DI) are also a key determinant of generating successful profiles. Seminal stains from the study by Bini and colleagues in 2015, were samples three decades after the crime, with different degradation ratios. Mini STR profiling yielded full profiles for most of the samples, in comparison to autosomal, Y-STR and RM Y-STR profiling $^{27}$.

A study by Hara and colleagues in 2015, used seminal stains of different ages $(33,50$ and 60 years) and different degradation ratios. For the DI ratio of 0.0044 , autosomal and Y-STR profiling had extremely low 
success rates in comparison to the impeccable sensitivity of mini STR's which gave a minor decrease (8/9) in successful profiles, which outlines that the age of the sample alone, doesn't govern the successful profiles generated, rather, the DI ratio does and the volume of the sample available also contribute. Thus, in low DI ratios, mini STR proves advantageous over autosomal and $\mathrm{Y}$ STR profiling ${ }^{28}$.

\section{Deletion Insertion Polymorphism STR Profiling}

Genetic identification of DNA using autosomal or Y-STR profiling is a major problem when the DNA of interest is a minor component in the mixture. (Table 2) $6,7,29,30$. Hence, the reason for the implementation of DIP-STRs into casework recently. They are deletion/ insertion polymorphisms linked to a microsatellite to selectively identify minor DNA fraction even at a very low minor DNA to major DNA ratio ${ }^{29,31,32}$.

Table 2: The ability of STR profiling techniques identify minor DNA in mixtures. ${ }^{6,7,29,30}$

\begin{tabular}{|c|c|}
\hline STR profiling technique & Minor DNA: Major DNA ratio \\
\hline Mini STR & $1: 10$ \\
\hline Autosomal STR & $1: 20$ \\
\hline Autosomal STR with fluorescent & $1: 50$ \\
\hline cell sorting & $1: 2000$ \\
\hline Y-STR & $1: 16000$ \\
\hline DIP-STR & \\
\hline
\end{tabular}

In 2017, Oldoni, Castella and Hall demonstrated the first use of DIP-STRs in sexual assault evidence, when both, Y-STR and autosomal STR couldn't identify minor DNA in mixtures. In one of their cases described, the sample was taken from the defendant's tracksuit crotch area, to test if the complainant's DNA was present. Y-STR profiling would not have been able to distinguish female DNA, and autosomal STR profiling only gave a profile for the male. Hence three DIP-STRs were used and identified the female DNA which was the minor DNA in the mixture, illustrating that DIP-STRs can be used in challenging sample mixtures to analyse minor DNA components $^{29}$. In another case described by the same authors, a vaginal swab was collected three days after the assault and analysed with ten DIP-STRs, where the major DNA component was in 16,000-fold excess. The full Y-STR profile was generated for the defendant, and seven DIPSTRs provided informative leads and

correlated with the Y-STR profile. However, the three other DIP-STRs generated non-specific PCR amplifications, leaving its sensitivity comparable to Y-STR profiling. Suggestive that, further validation is desired for DIP-STR profiling for extremely low DNA components in mixtures ${ }^{29}$.

\section{CONCLUSION}

In consideration with the cases discussed, the analysis of a higher number of Y-STR loci should be implemented, since this will yield additional discriminatory power and statistical grounding to confirm if it is a coincidental mismatch or not. Since Y-STR profiling is not individual specific, autosomal or DIP-STRs should be used in parallel, if one method fails. 
Retrieval of samples shortly after the crime, cannot always be expected. Therefore, the development of a 'mini RM Y-STR' marker can be suggested to be used in combination with autosomal STRs or DIP-STRs to target degraded DNA and specifically resolve male components in mixtures. This would help counteract the disadvantages of each STR marker, and have great promise in minimising the chances of wrongful conviction in the future.

\section{REFERENCES}

1. Muruganandhan J, Sivakumar G. Practical aspects of DNA-based forensic studies in dentistry. Journal of Forensic Dental Sciences. 2011;3(1):38-45. DOI: 10.4103/0975-1475.85295

2. Manamperi A, Hapaurachchi C, Gunawardene N, Bandara A, Dayanath D, Abeyewickreme W. STR polymorphisms in Sri Lanka: evaluation of forensic utility in identification of individuals and parentage testing. Ceylon Medical Journal. 2009;54(3):85-90. DOI: 10.4038/cmj.v54i3.1201

3. Hampikian G, West E, Akselrod O. The genetics of innocence: Analysis of 194 U.S. DNA exonerations. Annual Review of Genomics and Human Genetics. 2011;12(1):97-120. DOI: 10.1146/annurevgenom-082509-141715

4. Penumajji S, Bobbarala V, Naidu C. A case study of sexual assault by DNA finger printing technology using PCR based STR analysis. Journal of Pharmacy Research. 2009;2(6): 1079-1082.

5. Gymrek M, Willems T, Reich D, Erlich Y. Interpreting short tandem repeat variations in humans using mutational constraint. Nature Genetics. 2017;49(10):1495-1501. DOI: $10.1038 /$ ng.3952

6. McDonald A, Jones E, Lewi s J, O'Rourke P. Y-STR analysis of digital and/or penile penetration cases with no detected spermatozoa. Forensic Science
International: Genetics. 2015;15:84-89. DOI: 10.1016/j.fsigen.2014.10.015

7. Mulero J, Chang C, Lagacé R, Wang D, Bas J, McMahon T, Hennessy L. Development and validation of the AmpFeSTR ${ }^{\circledR}$ MiniFilerTM PCR amplification kit: A miniSTR multiplex for the analysis of degraded and/or PCR inhibited DNA*. Journal of Forensic Sciences. 2008;53(4):838-852. DOI: $10.1111 /$ j.15564029.2008.00760.x

8. Hanson E, Ballantyne J. An ultra-high discrimination Y chromosome short tandem repeat multiplex DNA typing system. PLoS ONE. 2007;2(8):e688. DOI: 10.1371/journal.pone.0000688

9. Góes A, Silva D, Domingues C, Marreiro Sobrinho J, Carvalho E. Identification of a criminal by DNA typing in a rape case in Rio de Janeiro, Brazil. Sao Paulo Medical Journal. 2002;120(3):77-79. DOI: 10.1590/s1516-31802002000300004

10. Jakovski Z, Jankova R, Duma A, Janeska B, Pavlovski G, Marjanovic D. Forensic approach to analyzing rape cases. Forensic Science International: Genetics Supplement Series. 2013;4(1):e45-e46. DOI: 10.1016/j.fsigss.2013.10.023

11. Hampikian G, Peri G, Lo S, Chin M, Liu K. Case report: Coincidental inclusion in a 17locus Y-STR mixture, wrongful conviction and exoneration. Forensic Science International: Genetics. 2017;31:1-4. DOI: 10.1016/j.fsigen.2017.08.004

12. Zoete J, Sjerps M, Meester R, Cator E. The combined evidential value of autosomal and Y-chromosomal DNA profiles obtained from the same sample. International Journal of Legal Medicine. 2014;128(6):897-904. DOI: $10.1007 / \mathrm{s} 00414-014-0971-7$

13. Hanson E, Berdos P, Ballantyne J. Testing and evaluation of 43 "Noncore" $\mathrm{Y}$ chromosome markers for forensic casework applications. Journal of Forensic Sciences. 2006;51(6):1298-1314.

DOI: 
14. Purps J, Geppert M, Nagy M, Roewer L. Validation of a combined autosomal/Ychromosomal STR approach for analyzing typical biological stains in sexual-assault cases. Forensic Science International: Genetics. 2015;19:238-242. DOI: $10.1016 /$ j.fsigen.2015.08.002

15. Ballantyne $K$, Goedbloed $M$, Fang $R$, Schaap O, Lao O, Wollstein A, et al. Mutability of Y-chromosomal microsatellites: rates, characteristics, molecular bases, and forensic implications. American Journal of Human Genetics. 2010;87(3):341-53. DOI: 10.1016/j.ajhg.2010.08.006

16. Ballantyne K, Keerl V, Wollstein A, Choi $\mathrm{Y}$, Zuniga S, Ralf A, V, et al. A new future of forensic Y-chromosome analysis: Rapidly mutating Y-STRs for differentiating male relatives and paternal lineages. Forensic Science International: Genetics. 2012;6(2):208-218. DOI: 10.1016/j.fsigen.2011.04.017

17. Adnan A, Ralf A, Rakha A, Kousouri N, Kayser M. Improving empirical evidence on differentiating closely related men with RM Y-STRs: A comprehensive pedigree study from Pakistan, Forensic Science International: Genetics. 2016;25:45-51. DOI: 10.1016/j.fsigen.2016.07.005

18. Delfin F, Madrid B, Tan M, De Ungria M. Y-STR analysis for detection and objective confirmation of child sexual abuse. International Journal of Legal Medicine. 2004;119(3):158-163.

DOI: 10.1007/s00414-004-0503-y

19. Hanson E, Ballantyne J. A Y-short tandem repeat specific DNA enhancement strategy to aid the analysis of late reported ( $\geq 6$ days) sexual assault cases. Medicine, Science and the Law. 2014;54(4):209-218. DOI: $10.1177 / 0025802413519761$

20. Mayntz-Press K, Sims L, Hall A, Ballantyne J. Y-STR profiling in extended interval $(\geq 3$ days) postcoital cervicovaginal samples. Journal of Forensic Sciences. 2008;53(2):342-348. DOI: $10.1111 /$ j.15564029.2008.00672.x
21. Kitayama T, Fujii K, Nakahara H, Mizuno N, Kasai K, Yonezawa N, et al. Estimation of the detection rate in STR analysis by determining the DNA degradation ratio using quantitative PCR. Legal Medicine. 2013;15(1):1-6.

DOI:

10.1016/j.legalmed.2012.07.003

22. Morgan J. Comparison of cervical Os versus vaginal evidentiary findings during sexual assault exam. Journal of Emergency Nursing. 2008;34(2):102-105. DOI: $10.1016 /$ j.jen.2007.04.022

23. El-Alfy S, Abd El-Hafez A. Paternity testing and forensic DNA typing by multiplex STR analysis using ABI PRISM 310 Genetic Analyzer. Journal of Genetic Engineering and Biotechnology. 2012;10(1):101-112. DOI: 10.1016/j.jgeb.2012.05.001

24. Constantinescu C, Barbarii L, Iancu C, Constantinescu A, Iancu D, Girbea G. Challenging DNA samples solved with MiniSTR analysis. Brief overview. Romanian Journal of Legal Medicine. 2012;20(1):51-56.

DOI: $10.4323 / \mathrm{rj} l \mathrm{~m} .2012 .51$

25. Thanakiatkrai P, Raham K, Pradutkanchana J, Sotthibandhu S, Kitpipit T. Direct-STR typing from presumptively-tested and untreated body fluids. Forensic Science International: Genetics. 2017;30:1-9. DOI: 10.1016/j.fsigen.2017.06.001

26. Hall D, Roy R. An evaluation of direct PCR amplification. Croatian Medical Journal. 2014;55(6):655-661.

DOI: $10.3325 / \mathrm{cmj} .2014 .55 .655$

27. Bini C, Ceccardi S, Trento C, D'Oria C, Carano F, Riccardi L, et al. Analysis of aged seminal stains by current forensic DNA approach. Forensic Science International: Genetics Supplement Series. 2015;5:e248e249. DOI: https://doi.org/10.1016/ j.fsigss.2015.09.099

28. Hara M, Nakanishi H, Takahashi S, Nagai A, Yamamoto $\mathrm{T}$, Yoneyama $\mathrm{K}$, et al. Relationship between DNA degradation ratios and the number of loci detectable bYSTR kits in extremely old seminal stain 
samples. Legal Medicine. 2015;17(5):391393. DOI: 10.1016/j.legalmed.2015.05.008

29. Oldoni F, Castella V, Hall D. Application of DIP-STRs to sexual/physical assault investigations: Eight case reports. Forensic Science International: Genetics. 2017;30:106-113.

DOI:

10.1016/j.fsigen.2017.06.010

30. Xu Y, Xie J, Chen R, Cao Y, Ping Y, Xu Q, et al. Fluorescence- and magnetic-activated cell sorting strategies to separate spermatozoa involving plural contributors from biological mixtures for human identification. Scientific Reports. 2016;6(1). DOI: $10.1038 /$ srep36515
31. Cereda G, Biedermann A, Hall D, Taroni F. An investigation of the potential of DIPSTR markers for DNA mixture analyses. Forensic Science International: Genetics. 2014;11:229-240.

DOI: 10.1016/j.fsigen.2014.04.001

32. Castella V, Gervaix J, Hall D. DIP-STR: Highly sensitive markers for the analysis of unbalanced genomic mixtures. Human Mutation. 2013. DOI: 10.1002/humu.22280 